\title{
Zinc Oxide Nanoparticle Photodetector
}

\author{
Sheng-Po Chang', 2 and Kuan-Jen Chen ${ }^{3}$ \\ ${ }^{1}$ Center for Micro/Nano Science and Technology and Advanced Optoelectronic Technology Center, National Cheng Kung University, \\ Tainan 70101, Taiwan \\ ${ }^{2}$ Department of Electrical Engineering \& Institute of Microelectronics, National Cheng Kung University, Tainan 70101, Taiwan \\ ${ }^{3}$ The Instrument Development Center, National Cheng Kung University, Tainan 701, Taiwan
}

Correspondence should be addressed to Sheng-Po Chang, changsp@mail.ncku.edu.tw

Received 24 January 2012; Revised 17 May 2012; Accepted 18 May 2012

Academic Editor: Michael $\mathrm{Hu}$

Copyright (C) 2012 S.-P. Chang and K.-J. Chen. This is an open access article distributed under the Creative Commons Attribution License, which permits unrestricted use, distribution, and reproduction in any medium, provided the original work is properly cited.

\begin{abstract}
A zinc oxide $(\mathrm{ZnO})$ nanoparticle photodetector was fabricated using a simple method. Under a $5 \mathrm{~V}$ applied bias, its dark current and photocurrent were $1.98 \times 10^{-8}$ and $9.42 \times 10^{-7} \mathrm{~A}$, respectively. In other words, a photocurrent-to-dark-current contrast ratio of 48 was obtained. Under incident light at a wavelength of $375 \mathrm{~nm}$ and a $5 \mathrm{~V}$ applied bias, the detector's measured responsivity was $3.75 \mathrm{~A} / \mathrm{W}$. The transient time constants measured during the turn-ON and turn-OFF states were $\tau_{\mathrm{ON}}=204 \mathrm{~s}$ and $\tau_{\mathrm{OFF}}=486 \mathrm{~s}$, respectively.
\end{abstract}

\section{Introduction}

As the number of scaled-down components being developed gradually increases, it is apparent that high-quality widebandgap one-dimensional (1D) semiconductor nanostructures such as nanowires (NWs) [1-6], nanotubes [7, 8], and nanoribbons $[9,10]$ will most likely become promising functional components for next-generation nanometer-scale photonic and electronic devices. In recent years, semiconductor nanocrystals and NWs have been used to fabricate photoelectric devices owing to their large surface-to-volume ratio and tunable feature size [11-15]. Accordingly, the presence of deep-level surface trap states in NWs greatly prolongs the photocarrier lifetime, and the reduced dimensionality of the active area in NW devices shortens the carrier transit time. Although the surface and feature size of NWs can provide benefits similar to those associated with nanocrystals, better extraction of photogenerated carriers, and thus a substantial photoconductive gain, can be achieved only through a high-mobility NW core.

Among the available semiconductor materials, zinc oxide $(\mathrm{ZnO})$ is one of the most appealing candidates because of its large exciton binding energy of $60 \mathrm{meV}$, wide bandgap energy of $3.37 \mathrm{eV}$ at room temperature, excellent chemical and thermal stability, and biocompatibility $[16,17]$. In the past decade, the demonstration of a large variety of functional $\mathrm{ZnO} \mathrm{NW}$ devices, such as field-effect transistors [14, 18$21]$, optically pumped lasers [22, 23], UV detectors [24-26], and chemical and biological sensors [25, 26], has attracted growing interest in this material. Law et al. [11] reported the use of aligned $\mathrm{ZnO}$ NWs in dye-synthesized solar cells to enhance the extraction of generated carriers, leading to higher external quantum efficiencies. In this work, $\mathrm{ZnO}$ nanoparticle UV photodetectors (PDs) were fabricated. The details of $\mathrm{ZnO}$ nanoparticle growth and detector fabrication are discussed. The electrical and optical characteristics of the fabricated PDs are also measured and analyzed.

\section{Experiments}

Well-dispersed nanoscale $\mathrm{ZnO}$ suspensions were obtained using ball milling equipment. The milling conditions were $3500 \mathrm{rpm}$ and $24 \mathrm{~h}$. The prepared $\mathrm{ZnO}$ nanoparticles were spin-coated on an $\mathrm{Al}_{2} \mathrm{O}_{3}$ substrate. Next, the resulting $\mathrm{ZnO}$ nanoparticle thin films were dried at $60^{\circ} \mathrm{C}$ in an oven. The baked films and substrates were annealed at $800^{\circ} \mathrm{C}$ for $1 \mathrm{~h}$ in air. The films were analyzed by scanning electron microscopy (SEM), X-ray diffraction (XRD), and photoluminescence (PL) equipment. A JEOL JSM-7000 F field-emission scanning electron microscope operated at $10 \mathrm{keV}$ was then used 


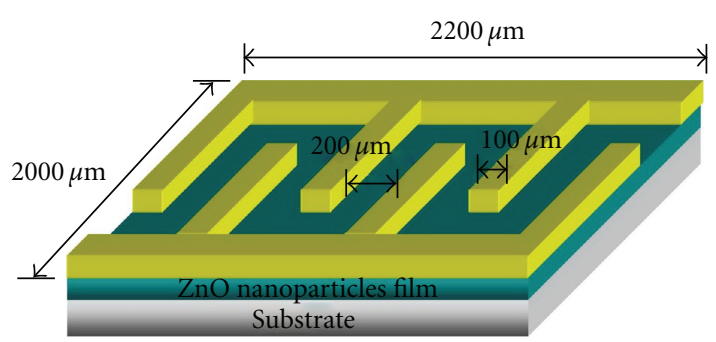

FIgURE 1: Schematic diagram of the fabricated $\mathrm{ZnO}$ nanoparticle photodetector.

to characterize their structural properties. To fabricate the nanoparticle PD, a thick Ni-Au $(20 / 100 \mathrm{~nm})$ film was deposited through an interdigitated shadow mask onto the nanoparticle thin film to serve as contact electrodes. We designed the pattern on the metal mask such that the fingers of the interdigitated electrodes were $2 \mathrm{~mm}$ wide and $2.2 \mathrm{~mm}$ long with a finger spacing of $0.2 \mathrm{~mm}$. The monochromic light was then illuminated onto the fabricated PD with an active area of $4.4 \mathrm{~mm}^{2}$. It should be noted that the nanoparticle thin film shown in Figure 1 could provide electrical paths for the two interdigitated electrodes. The current-voltage $(I-V)$ characteristics of the fabricated PDs were then measured by an HP 4156 semiconductor parameter analyzer at room temperature. The spectral responsivity of the PDs was also measured at room temperature by a Jobin-Yvon SPEX System with a $300 \mathrm{~W}$ xenon arc lamp light source (PerkinElmer PE300BUV) and a standard synchronous detection scheme.

\section{Results and Discussion}

Figure 2(a) shows SEM images of $\mathrm{ZnO}$ nanoparticles annealed at $400^{\circ} \mathrm{C}$. The shapes of the nanoparticles were clearly spherical and column-like, and the average grain size was about $100 \mathrm{~nm}$. These $\mathrm{ZnO}$ nanoparticles were in close contact with each other, forming a continuous film with an observable thickness of about $500 \mathrm{~nm}$. Figure 2(b) shows SEM images of $\mathrm{ZnO}$ nanoparticles annealed at $600^{\circ} \mathrm{C}$. The grain size was about $150 \mathrm{~nm}$, and the shapes of the nanoparticles were also spherical and column-like. Figure 2(c) shows SEM images of $\mathrm{ZnO}$ nanoparticles annealed at $800^{\circ} \mathrm{C}$. The nanoparticles were clearly in closer contact and melted together. Because of the high-temperature annealing, the crystallization properties were much better than those obtained at lower temperatures. Figure 3(a) shows the XRD spectrum of the $\mathrm{ZnO}$ nanoparticle film on the $\mathrm{Al}_{2} \mathrm{O}_{3}$ substrate. All the diffraction peaks of $\mathrm{ZnO}$ nanoparticles and $\mathrm{Al}_{2} \mathrm{O}_{3}$ could be indexed to the wurtzite structure $\mathrm{ZnO}$ and $\mathrm{Al}_{2} \mathrm{O}_{3}$ according to the standard JCPDS cards (no. 897716 and no. 751526). Figure $3(\mathrm{~b})$ shows the range of energydispersive X-ray (EDX) spectrum detection in the $\mathrm{ZnO}$ nanoparticle film. We confirmed that the $\mathrm{ZnO}$ nanoparticles contained $31.5 \%$ zinc, $34.14 \%$ oxygen, $21.96 \%$ aluminum, $7.35 \%$ platinum, and $5.04 \%$ carbon by weight. The platinum $(\mathrm{Pt})$ signals originated from the deposited platinum thin film that was used to increase the electric conductivity during

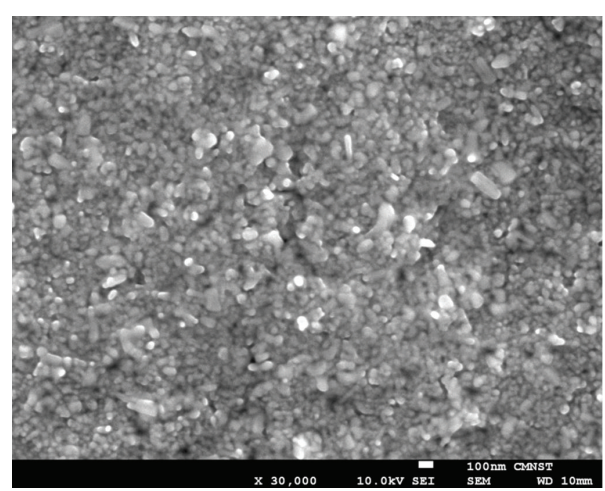

(a)

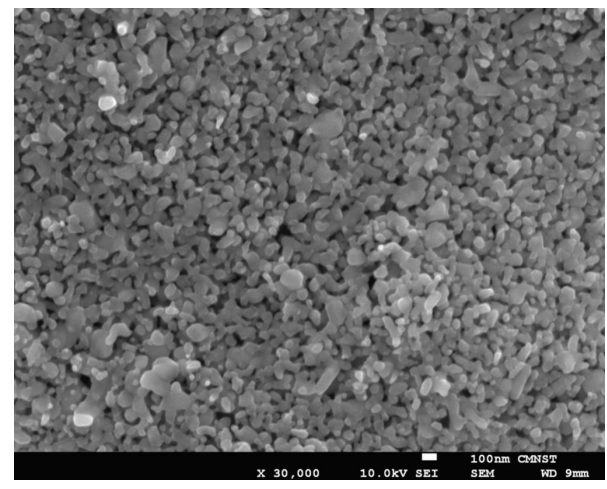

(b)

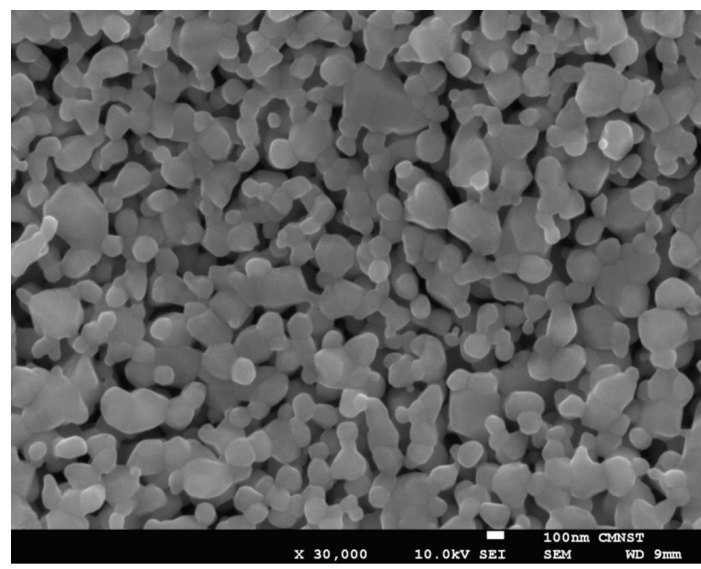

(c)

Figure 2: SEM images of $\mathrm{ZnO}$ nanoparticle film on $\mathrm{Al}_{2} \mathrm{O}_{3}$ substrate after annealing at (a) $400^{\circ} \mathrm{C}$, (b) $600^{\circ} \mathrm{C}$, and (c) $800^{\circ} \mathrm{C}$.

SEM imaging. Because the nanoparticle film was $500 \mathrm{~nm}$ thick, the aluminum and oxygen content were attributed to the $\mathrm{Al}_{2} \mathrm{O}_{3}$ substrate. After the oxygen in $\mathrm{Al}_{2} \mathrm{O}_{3}$ was subtracted, the ratio of zinc to oxygen was still about $1: 1$.

Figure 4 shows the current-voltage $(I-V)$ characteristics between two neighboring electrode bridges for a $\mathrm{ZnO}$ nanoparticle film measured in the dark and under UV illumination. Under a $5 \mathrm{~V}$ applied bias, the dark current and photocurrent of our $\mathrm{ZnO}$ nanoparticle $\mathrm{PD}$ were $1.98 \times 10^{-8}$ and $9.42 \times 10^{-7} \mathrm{~A}$, respectively. In other words, we obtained a photocurrent-to-dark-current contrast ratio of 48 . When the 


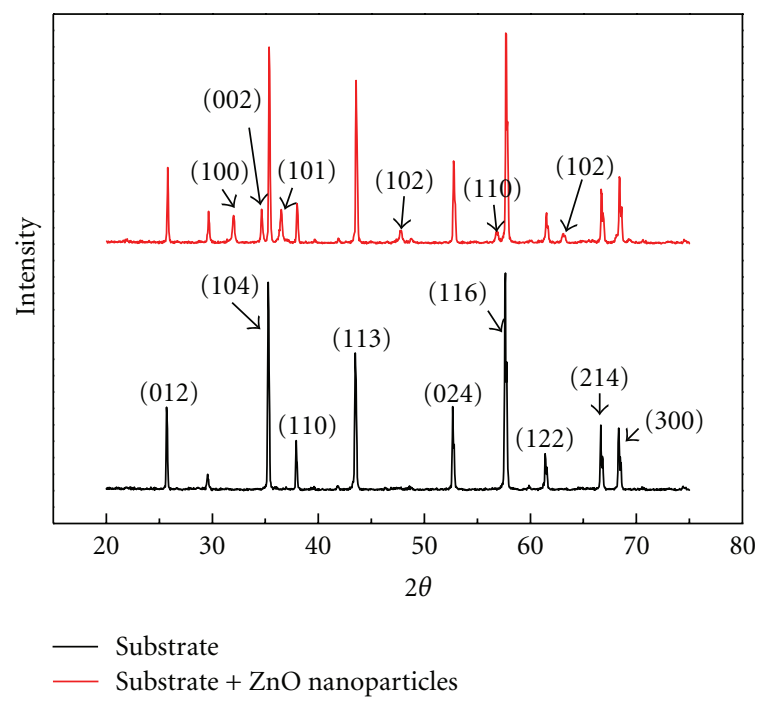

(a)

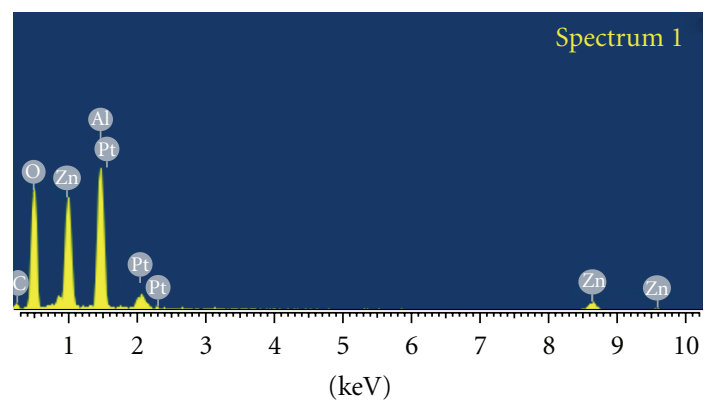

(b)

FIgURE 3: (a) XRD and (b) EDX spectra of $\mathrm{ZnO}$ nanoparticle film on $\mathrm{Al}_{2} \mathrm{O}_{3}$ substrate.

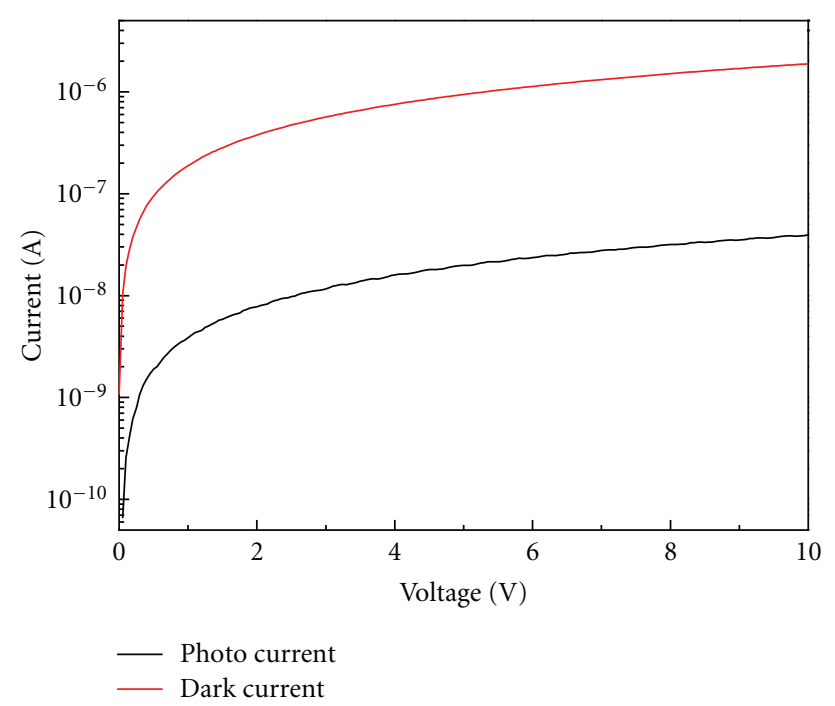

Figure 4: $I-V$ characteristics of the fabricated $\mathrm{ZnO}$ nanoparticle photodetector after annealing at $800^{\circ} \mathrm{C}$.

sample was irradiated with UV light at room temperature, the conductance rose, as shown in Figure 5. The first time the film was irradiated, a shift in the dark conductivity occurred that was maintained during subsequent irradiations. As shown in Figure 5, the dynamic response of the $\mathrm{ZnO}$ nanoparticle PD was stable and reproducible, with an on/off current contrast ratio of around 160 . The photocurrent decayed rapidly and could be well described by a stretched exponential function. From the data plotted in Figure 5, it was found that the corresponding time constant for turn-ON transient was $\tau_{\mathrm{ON}}=204 \mathrm{~s}$, while that for turn-OFF transient was $\tau_{\mathrm{OFF}}=486 \mathrm{~s}$. It should be noted that the current decrease rate is determined by the speed of oxygen molecule absorption on the $\mathrm{ZnO}$ nanoparticle surface, which captures excess

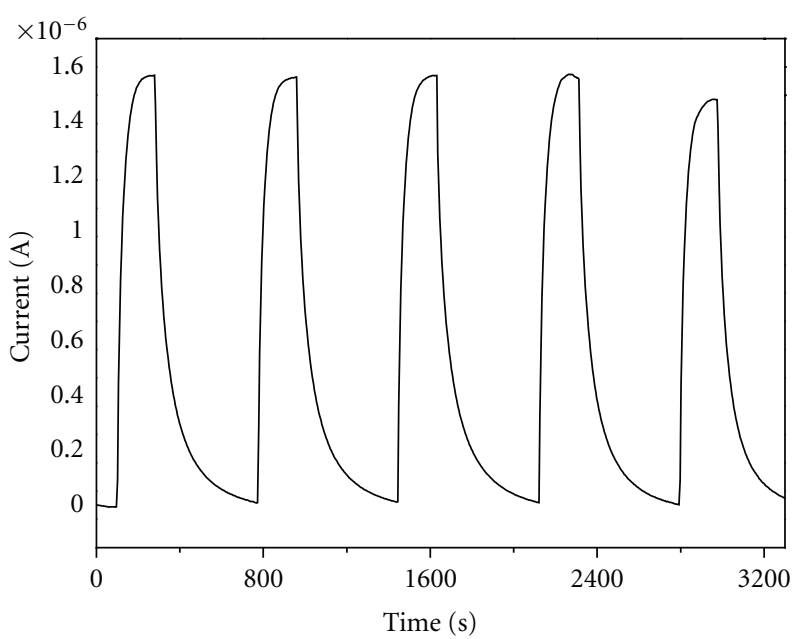

Figure 5: Transient response of the measured current under intermittent UV illumination.

electrons. Thus, the turn-off speed should be much slower than the turn-on speed for our ZnO UV PD. It should be noted that the turn-OFF transient time constant observed in this study was much smaller than that reported by Martins et al. [27]. The faster response indicates that the $\mathrm{ZnO}$ nanoparticle photodetector is suitable for high-speed operation.

Figure 6 shows the room-temperature spectral responses of the fabricated $\mathrm{ZnO}$ nanoparticle PD to a 300-W Xe lamp dispersed by a monochromator used as the excitation source. During these measurements, the monochromatic light was calibrated by a UV-enhanced Si diode, and an optical power meter was modulated by a mechanical chopper and collimated onto the front side (i.e., the metal side) of the fabricated devices using an optical fiber. The photocurrent was then recorded by a lock-in amplifier. It should be noted 


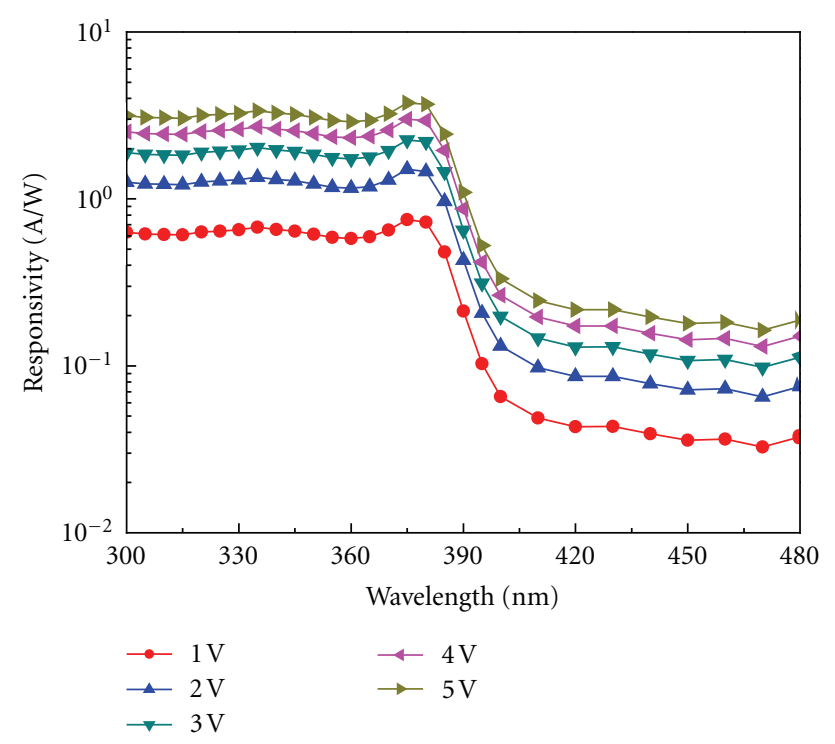

Figure 6: Room-temperature spectral responses of the $\mathrm{ZnO}$ nanoparticle photodetector measured at different applied biases.

that the PD's photoresponses were flat in the short wavelength region, whereas a sharp cutoff occurred at $375 \mathrm{~nm}$. Under incident light at a wavelength of $375 \mathrm{~nm}$ and a $5 \mathrm{~V}$ applied bias, the PD's measured responsivity was $3.75 \mathrm{~A} / \mathrm{W}$, indicating that the high responsivity corresponds to the photoconductive gain. Previously, Chen et al. observed an ultrahigh photoconductive gain from a single GaN NW, which was three orders of magnitude larger than that of a GaN film PD [28]. The large photoconductive gain has also been shown to originate from carrier multiplication and the electron-hole spatial separation induced by strong surface band bending. Similar phenomena should also occur in our $\mathrm{ZnO}$ nanoparticle $\mathrm{PD}$. The results suggest that the $\mathrm{ZnO}$ nanoparticle PD reported in this study is potentially useful for UV light sensing.

\section{Conclusion}

In summary, a zinc oxide $(\mathrm{ZnO})$ nanoparticle PD was fabricated using a simple method. Under incident light at a wavelength of $375 \mathrm{~nm}$ and a $5 \mathrm{~V}$ applied bias, the PD's measured responsivity was $3.75 \mathrm{~A} / \mathrm{W}$. The transient time constants measured during the turn-ON and turn-OFF states were $\tau_{\mathrm{ON}}=204 \mathrm{~s}$ and $\tau_{\mathrm{OFF}}=486 \mathrm{~s}$, respectively.

\section{Acknowledgments}

The authors would like to thank the National Science Council and Bureau of Energy, Ministry of Economic Affairs of Taiwan. For the financial support under Contracts nos. 1002221-E-006-168 and 101-D0204-6 and the LED Lighting Research Center of NCKU for the assistance of device characterization. This work was also supported in part by the Center for Frontier Materials and Micro/Nano Science and Technology, the National Cheng Kung University, Taiwan.
This work was also supported in part by the Advanced Optoelectronic Technology Center, the National Cheng Kung University, under projects from the Ministry of Education.

\section{References}

[1] Y. Huang, X. Duan, Q. Wei, and C. M. Lieber, "Directed assembly of one-dimensional nanostructures into functional networks," Science, vol. 291, no. 5504, pp. 630-633, 2001.

[2] W. Lu and C. M. Lieber, "Nanoelectronics from the bottom up," Nature Materials, vol. 6, no. 11, pp. 841-850, 2007.

[3] M. H. Huang, S. Mao, H. Feick et al., "Room-temperature ultraviolet nanowire nanolasers," Science, vol. 292, no. 5523, pp. 1897-1899, 2001.

[4] F. Qian, Y. Li, S. Gradečak, D. Wang, C. J. Barrelet, and C. M. Lieber, "Gallium nitride-based nanowire radial heterostructures for nanophotonics," Nano Letters, vol. 4, no. 10, pp. 1975-1979, 2004.

[5] P. V. Radovanovic, C. J. Barrelet, S. Gradečak, F. Qian, and C. M. Lieber, "General synthesis of manganese-doped II-VI and III-V semiconductor nanowires," Nano Letters, vol. 5, no. 7, pp. 1407-1411, 2005.

[6] Y. Cui, Z. Zhong, D. Wang, W. U. Wang, and C. M. Lieber, "High performance silicon nanowire field effect transistors," Nano Letters, vol. 3, no. 2, pp. 149-152, 2003.

[7] L. C. Qin, X. Zhao, K. Hirahara, Y. Miyamoto, Y. Ando, and S. Iijima, "Materials science: the smallest carbon nanotube," Nature, vol. 408, no. 6808, p. 50, 2000.

[8] N. Wang, Z. K. Tang, G. D. Li, and J. S. Chen, "Materials science: single-walled $4 \AA$ carbon nanotube arrays," Nature, vol. 408 , no. 6808 , pp. 50-51, 2000.

[9] Z. W. Pan, Z. R. Dai, and Z. L. Wang, "Nanobelts of semiconducting oxides," Science, vol. 291, no. 5510, pp. 1947-1949, 2001.

[10] Y. Liu, J. A. Zapien, Y. Y. Shan, C. Y. Geng, C. S. Lee, and S. T. Lee, "Wavelength-controlled lasing in $\mathrm{Zn}^{x} \mathrm{Cd}^{1-x} \mathrm{~S}$ singlecrystal nanoribbons," Advanced Materials, vol. 17, no. 11, pp. 1372-1377, 2005.

[11] M. Law, L. E. Greene, J. C. Johnson, R. Saykally, and P. Yang, "Nanowire dye-sensitized solar cells," Nature Materials, vol. 4, no. 6, pp. 455-459, 2005.

[12] S. A. Mcdonald, G. Konstantatos, S. Zhang et al., "Solutionprocessed $\mathrm{PbS}$ quantum dot infrared photodetectors and photovoltaics," Nature Materials, vol. 4, no. 2, pp. 138-142, 2005.

[13] I. L. Medintz, H. T. Uyeda, E. R. Goldman, and H. Mattoussi, "Quantum dot bioconjugates for imaging, labelling and sensing," Nature Materials, vol. 4, no. 6, pp. 435-446, 2005.

[14] W. K. Hong, J. I. Sohn, D. K. Hwang et al., "Tunable electronic transport characteristics of surface-architecture- controlled $\mathrm{ZnO}$ nanowire field effect transistors," Nano Letters, vol. 8, no. 3, pp. 950-956, 2008.

[15] J. B. Baxter and E. S. Aydil, "Nanowire-based dye-sensitized solar cells," Applied Physics Letters, vol. 86, no. 5, Article ID 053114, pp. 1-3, 2005.

[16] J. Chen, Y. Zhang, B. J. Skromme, K. Akimoto, and S. J. Pachuta, "Properties of the shallow O-related acceptor level in ZnSe," Journal of Applied Physics, vol. 78, no. 8, pp. 5109-5119, 1995.

[17] H. Kato, M. Sano, K. Miyamoto, and T. Yao, "Homoepitaxial growth of high-quality $\mathrm{Zn}$-Polar $\mathrm{ZnO}$ films by plasma-assisted molecular beam epitaxy," Japanese Journal of Applied Physics, vol. 42, no. 8 B, pp. L1002-L1005, 2003. 
[18] K. Keem, J. Kang, C. Yoon et al., "A fabrication technique for top-gate $\mathrm{ZnO}$ nanowire field-effect transistors by a photolithography process," Microelectronic Engineering, vol. 84, no. 58, pp. 1622-1626, 2007.

[19] W. Y. Weng, S. J. Chang, C. L. Hsu, and T. J. Hsueh, "A znonanowire phototransistor prepared on glass substrates," ACS Applied Materials and Interfaces, vol. 3, no. 2, pp. 162-166, 2011.

[20] P. F. Carcia, R. S. McLean, M. H. Reilly, and G. Nunes, “Transparent $\mathrm{ZnO}$ thin-film transistor fabricated by $\mathrm{rf}$ magnetron sputtering," Applied Physics Letters, vol. 82, no. 7, pp. 1117$1119,2003$.

[21] E. Fortunato, A. Gonçalves, A. Pimentel et al., "Zinc oxide, a multifunctional material: from material to device applications," Applied Physics A, vol. 96, no. 1, pp. 197-205, 2009.

[22] P. J. Pauzauskie and P. Yang, "Nanowire photonics," Materials Today, vol. 9, no. 10, pp. 36-45, 2006.

[23] B. Zou, R. Liu, F. Wang, A. Pan, L. Cao, and Z. L. Wang, "Lasing mechanism of $\mathrm{ZnO}$ nanowires/nanobelts at room temperature," Journal of Physical Chemistry B, vol. 110, no. 26, pp. 12865-12873, 2006.

[24] C. L. Hsu, S. J. Chang, Y. R. Lin et al., "Ultraviolet photodetectors with low temperature synthesized vertical $\mathrm{ZnO}$ nanowires," Chemical Physics Letters, vol. 416, no. 1-3, pp. 75-78, 2005.

[25] C. Soci, A. Zhang, B. Xiang et al., "ZnO nanowire UV photodetectors with high internal gain," Nano Letters, vol. 7, no. 4, pp. 1003-1009, 2007.

[26] J. Suehiro, N. Nakagawa, S. I. Hidaka et al., "Dielectrophoretic fabrication and characterization of a $\mathrm{ZnO}$ nanowire-based UV photosensor," Nanotechnology, vol. 17, no. 10, pp. 2567-2573, 2006.

[27] R. Martins, E. Fortunato, P. Nunes et al., "Zinc oxide as an ozone sensor," Journal of Applied Physics, vol. 96, no. 3, pp. 1398-1408, 2004.

[28] R.-S. Chen, H.-Y. Chen, C.-Y. Lu et al., "Ultrahigh photocurrent gain in m -axial GaN nanowires," Applied Physics Letters, vol. 91, no. 22, Article ID 223106, 2007. 

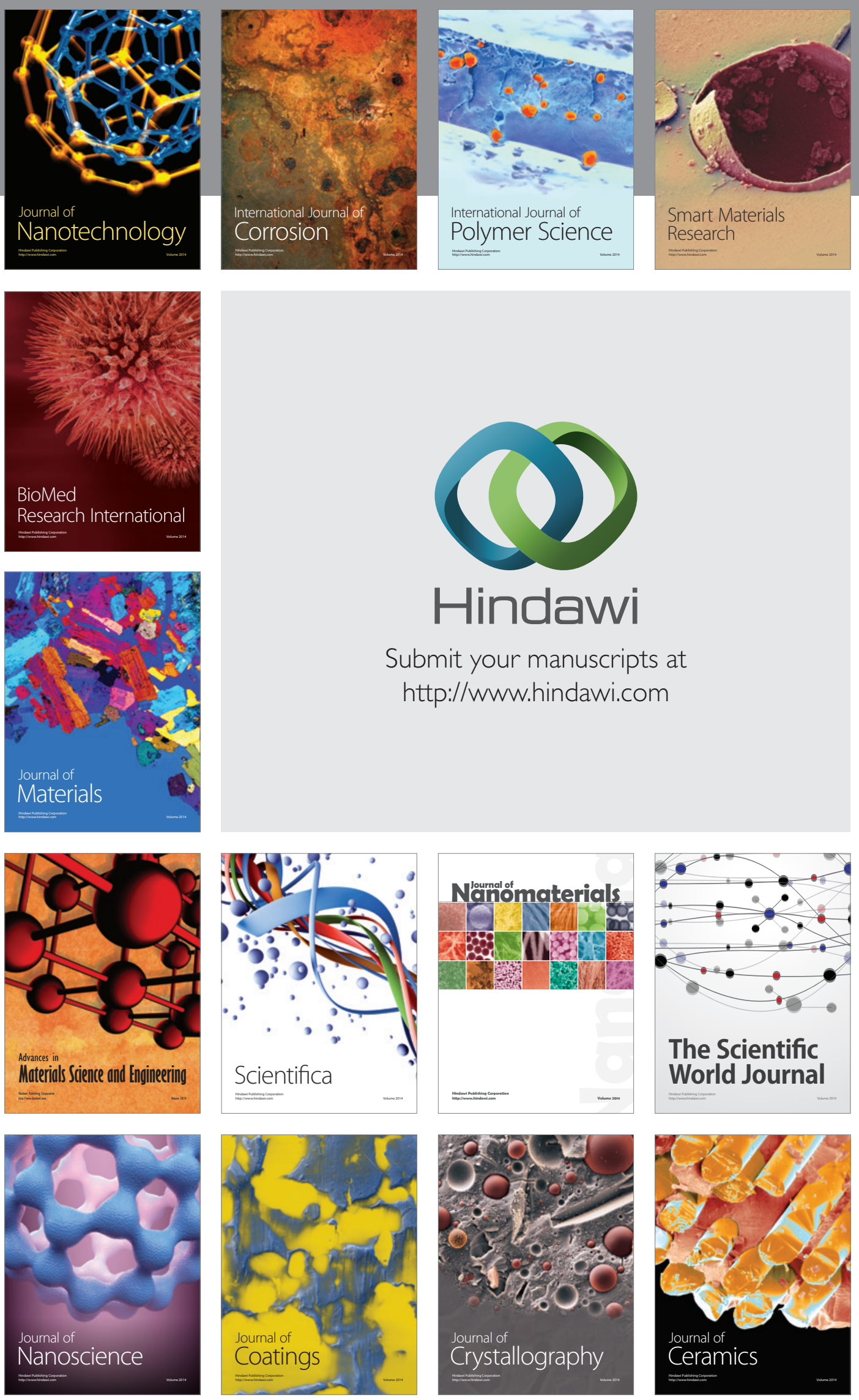

The Scientific World Journal

Submit your manuscripts at

http://www.hindawi.com

\section{World Journal}

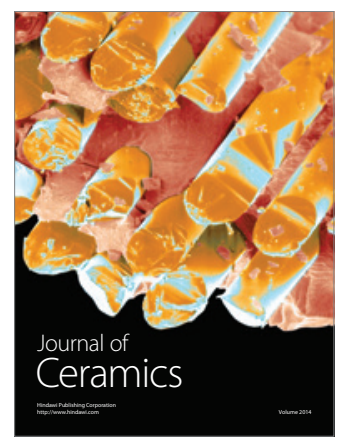

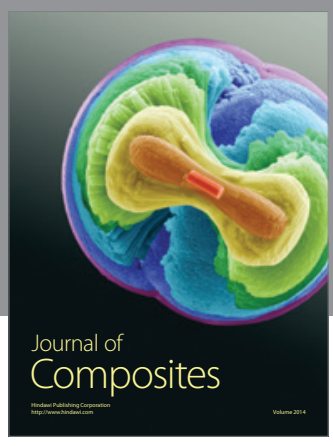
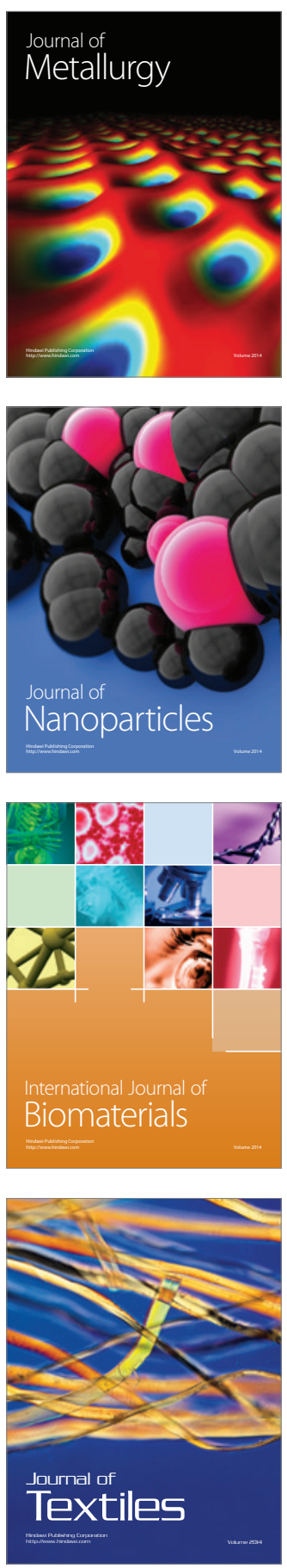